Available online at GSC Online Press Directory

GSC Biological and Pharmaceutical Sciences

e-ISSN: 2581-3250, CODEN (USA): GBPSC2

(RESEARCH ARTICLE)

\title{
Antidepressant in animal models of depression and study of cognitive property
}

\author{
Mankar Swapnali Suresh ${ }^{1,}{ }^{*}$, Turan Satish Premsingh ${ }^{2}$, Mankar Swapnil Suresh ${ }^{3}$ and Shelke Pradip Ashruji 1 \\ ${ }^{1}$ Department of Quality Assurance, Agnihotri College of Pharmacy, Wardha, Pin 442001 Maharashtra India. \\ 2 PDM School of Pharmacy, Karsindhu, Safidon, Jind 126112 Haryana, India. \\ 3 Jamanlal Goyanka Dental College and Hospital, Akola 444002 Maharashtra India.
}

Publication history: Received on 15 April 2019; revised on 15 June 2019; accepted on 20 June 2019

Article DOI: https://doi.org/10.30574/gscbps.2019.7.3.0069

\begin{abstract}
Depression characterized by significant depression of mood and impairment of function .In whole study evaluate the antidepressant activity of ethanolic extract of Bacopa monnieri Linn, to assess the pharmacodynamic interaction of drug with standard nootropic antidepressant, determine effect of drug alone and in combination with standard antidepressant in brain on amino acid neurotransmitter and acetylcholine esterase activity. Despair Swim test and tail suspension test study of interaction of ethanolic extract Bacopa monnieri with standard antidepressant drug extract used in FST and TST studied. Final perception was GABAmimetic Bacopa monneri decrease the immobility in forced swim test found that GABAergic activity lower in depressed state than normal brain. The control group in both FST and TST. GABA level found decrease than basal values. From experimental evidence it may conclude that ethanolic extract of Bacopa monnieri Linn possesses significant antidepressant activity.
\end{abstract}

Keywords: Bacopa monnieri Linn; Forced swim test; Tail suspension test; GABAergic activity

\section{Introduction}

The primary clinical manifestations of major depression are significant depression of mood and impairment of function. Some features of depressive disorders overlap those of the anxiety disorders, including panic-agoraphobia syndrome, severe phobias, generalized anxiety disorder, social anxiety disorder, posttraumatic stress disorder, and obsessive-compulsive disorder. Major depression is characterized by feelings of intense sadness and despair, mental slowing and loss of concentration, pessimistic worry, lack of pleasure, self-deprecation, and variable agitation or hostility. Physical changes also occur, particularly in severe, vital, or "melancholic" depression. These include insomnia or hypersomnia; altered eating patterns, with anorexia and weight loss or sometimes overeating; decreased energy and libido; and disruption of the normal circadian and ultradian rhythms of activity, body temperature, and many endocrine functions. As many as $10 \%$ to $15 \%$ of individuals with severe clinical depression, and up to $25 \%$ of those with bipolar disorder, display suicidal behaviour at some time Depressed patients usually respond to antidepressant drugs, or, in severe or treatment-resistant cases, to electroconvulsive therapy (ECT). In such disorders Antidepressants and sedative-antianxiety agents are commonly used to treat anxiety disorder. The etiology of depressive disorders is too complex to be totally explained by a single social, developmental or biologic theory, several factors appear to work together to cause or precipitate depressive disorders [1-5].

The symptoms reported by patients with major depression consistently reflect changes in brain monoamine neurotransmitters, specifically norepinephrine (NE), Serotonin (5-HT) and Dopamine (DA).

\footnotetext{
${ }^{*}$ Corresponding author

E-mail address: sonumankar51@gmail.com
} 


\section{Material and methods}

\subsection{Drugs, chemicals and solvent}

Acacia powder, acetic acid glacial, acetone, acetylcholine chloride, aspartic acid, benzene, 4-aminobutyric acid gaba, ammonia, chloroform, amitriptylene hydrochloride (I.P.), fluoxetine, ninhydrin reagent, silica gel for chromatography, silica gel 60 P 254 precoated TLC plates, toluene, phenol, ethanolic extract of Bacopa monnieri Linn. Leaves, distilled water, glutamic acid, hydrochloric acid, normal saline (0.9\%), ethyl alcohol (95\%), these chemicals used.

\subsection{Equipment and Instruments}

Cooling centrifuge, Fast refrigerator Tissue Homogenizer from REMI, Mumbai, Electric Dryer from Aditi associates, Rotary vaccum Evaporator from Medica Instr. Mumbai, Hot Air Oven from Lab.Hosp. Mumbai, Micropipette, 5-50 $\mu \mathrm{l}$ from Biosystem, Mumbai and TLC developing chamber are used.

\subsection{Laboratory animals}

Swiss albino mice are used of age about 6-8 weeks and in weight 18-23g, either male or female preferred for experimental purpose.

\section{$2.4 \quad$ Animal models of depression}

Forced Swim Test

Tail Suspension

\subsection{Methods used for brain neurochemical estimation $[2,3,4]$}

4-6 weeks old Female mice (females are generally more sensitive) having bod weights in the range of 25-30 grams wear randomly selected and marked to permit individual identification. The temperature in the experimental animal room was maintained ambient. For feeling, conventional rodent laboratory diets was used with an unlimited supply of drinking water. Animals are kept in the cages for at least 7 days prior to dosing for acclimatization to laboratory conditions. Animals wear fasted $24 \mathrm{hrs}$ prior to dosing tests substance wear administered to in a single dose by gavag using erogastric tube. The substance is administered to the set of five female mice at predetermined doses Animals wear observed individually after dosing at least once during the first 30minutes, periodically during the first $24 \mathrm{hrs}$, with special attention gives during the first $4 \mathrm{hrs}$.

\subsection{Despair swim test [5, 7]}

Male Sprague-Dawley rats weighing 160-180 g was used. They brought to the laboratory at least one day before the experiment and are housed separately in Makrolon cages with free access to food and water. Naive rats are individually forced to swim inside a vertical Plexiglas cylinder. Rats placed in the cylinders for the first time are initially highly active, vigorously swimming in circles, trying to climb the wall or diving to the bottom. After 2-3 min phases of immobility or floating of increasing length. After 5-6 min immobility reaches a plateau where the rats remain immobile for approximately $80 \%$ of the time. After $15 \mathrm{~min}$ in the water the rats are removed and allowed to dry in a heated enclosure $\left(32{ }^{\circ} \mathrm{C}\right)$ before being returned to their home cages. Again placed in the cylinder $24 \mathrm{~h}$ later and the total duration of immobility is measured during a $5 \mathrm{~min}$ test. Floating behaviour during this 5 min period has been found to be reproducible in different groups of rats. An animal is world be judge to be immobile whenever it remains floating passively in the water in a slightly hunched but upright position, its nose just above the surface. Test drugs or standard are administered one hour prior to testing. Since experiments with the standard drug (imipramine) showed that injections 1,5 and $24 \mathrm{~h}$ prior the test gave the most stable results in reducing floating these times are chosen for the experiment.

\subsection{Tail suspension test in mice [6]}

Male Balb/cJ mice weighing 20-25 g used preferentially. They are housed in plastic cages for at least10 days prior to testing in a $12 \mathrm{~h}$ light cycle with food and water freely available. Animals are transported from the housing room to the testing area the new environment for $1 \mathrm{~h}$ before testing. Groups of 10 animals wear treated with the test compounds or the vehicle by intraperitoneal injection 30 min prior to testing. For the test the mice are suspended on the edge of a shelf $58 \mathrm{~cm}$ above a table top by adhesive tape placed approximately $1 \mathrm{~cm}$ from the tip of the tail. The duration of immobility is record for a period of 5 min. Mice is considered immobile when they hang passively and completely motionless for at least $1 \mathrm{~min}$. 


\subsection{Methods for estimation of acetylcholine esterase activity in brain tissue $[5,6,8,9]$}

\subsubsection{Modification of method}

The original method describes the use of Acetylcholine chloride as a substance. But acetylthiocholine in place of acetylcholine is used regularly as a substance as the Acetylcholine Esterase has more affinity towards mid-atom as compared oxo-esters. Iodide with of acetylcholine instead of chloride is also utilized regularly. A choline esterase inhibitor serine can be utilized for assenting the instrument or a blank without substrate may also be used. It was found that the ratio of concentrations of DTNB/Ach is an important parameter for ACTH hydrolysis course as high excess of DTNB decreases the hydrolysis rate resulting in a lower measured enzyme activity.

\subsection{Methods used for brain neurochemical estimations}

\subsubsection{UV Spectrophotometry}

In that used signal unidirectional desendry technique of paper chromatographic separation and analysis derivitization for estimation of GABA by spectrophotometry at $570 \mathrm{~nm}$ developed on enzymatic assay for estimation of L-glutamic acid using glutamate dehydrogenase.

\subsubsection{Spectroflourimery}

The relative fluorescence of aspartic like Dopamine (330-375 nm), serotonin and Noradrenalin.

\subsection{HPLC and electrochemical estimation}

This method and technique is by other researchers with varying columns derivatives for specifications of effect of GABA.

\subsection{HPLC and UV Spectrophotometric detection}

We used with divinyl chloride and serotonin assembly for determination of GABA at $440 \mathrm{~nm}$.

\subsubsection{Microdialysis and Capillary electrophoresis}

Dissection and preservation of mouse Brain

The mice were sacrificed by cervical dislocation within one hour after experimentation, the whole brain were dissected out, weighed and kept in $0.01 \mathrm{~N} \mathrm{HCl}$ at-40 degree centigrade.

Homogenization of brain

The preserved brains wear homogenized with $5 \mathrm{ml} 0.01 \mathrm{~N} \mathrm{HCl}$ in a REMI homogenizer for $10 \mathrm{~min}$.

\subsection{TLC of Brain extract and separation of amino acids [11, 13, 14]}

$50 \mathrm{ml}$ of extract was applied to $5 \times 10 \mathrm{~cm}$ silica gel $60 \mathrm{P} 254$ percoated aluminium support chromatographic plates divided in three approximately equal spots and kept for development of unidirectional ascending chromatogram in a saturated chamber containing the mobile phase phenol saturated with water. After chromatogram was developed, the plate was dried thoroughly and it was sprayed with $0.5 \%$ ninhydrin reagent in absolute ethanol. This ninhydrin treated plate was kept in an oven at 60-70 degree centigrade for one hour for colour development.

\subsection{UV-visible spectrophotometric estimation of amino acids [12, 14]}

The purple blue spots developed at Rf value of 0.07-0.01, 0.13-0.16, 0.33-0.37 corresponding to aspartic acid, glutamic acid and GABA, were cut, the silica gel was scraped off in a test tube containing $2 \mathrm{ml}$ of $0.5 \%$ ninhydrin in absolute alcohol And treated on water bath for $5.10 \mathrm{~min}$. The volume was adjusted to $5 \mathrm{ml}$ with distilled water and absorbance was measured at $570 \mathrm{~nm}$ in JASCO double beam UV-visible spectrophotometer. 


\section{Results}

\subsection{Phytochemical tests for ethanolic extract of Bacoppa monnieri Linn.}

Table 1 Qualitative phytochemical analysis of ethanolic extract of Bacoppa monnieri Linn

\begin{tabular}{|c|c|c|c|}
\hline Sr. No. & Test & Observation & Interference \\
\hline 1 & Carbohydrates & $-\ldots-++$ & Present \\
\hline 2 & Proteins & - - - - $^{-}$ & Present \\
\hline 3 & Glycosides & ----++ & Present \\
\hline 4 & Flavonoids & ---++ & Present \\
\hline 5 & Alkaloids & $-\ldots+$ & Present \\
\hline 6 & Tannins \& phenol & $\ldots \ldots+$ & Present \\
\hline 7 & Steroids & $-\ldots+-+++$ & Present \\
\hline
\end{tabular}

\subsection{Preliminary thin layer chromatographic investigation of ethanolic extract of Bacoppa monnier Linn}

Mobile phase 1 (Left) _------ Tolune : ethyl Acetate: Diethylamine

$$
\text { (70) : (20) }
$$

Mobile phase 2 (Right) _------ Tolune : ethyl acetate

$$
\text { (70) : (30) }
$$

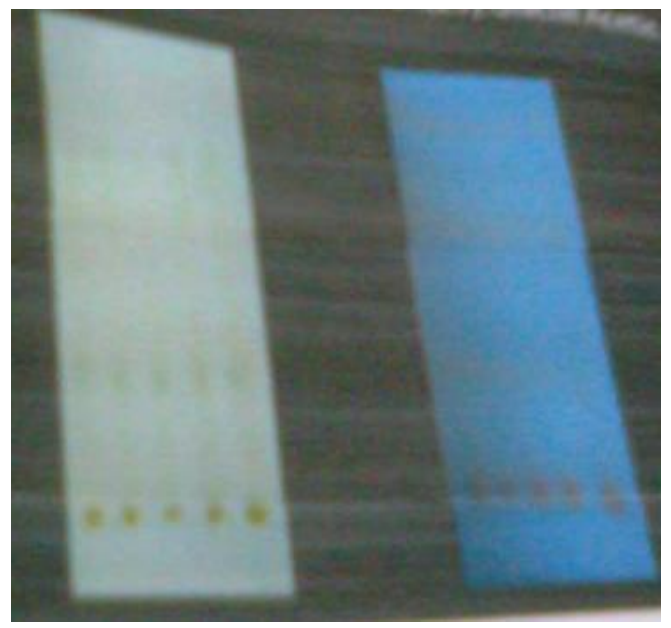

Figure 2 Thin layer chromatographic investigation

\subsection{Acute toxicity Study [15]}

In results it was concluded that the extract of Bacopa monnieri Linn. Is found safe, at the dose of $2000 \mathrm{mg} / \mathrm{kg}$. No sign of toxicity at a limit of $2000 \mathrm{mg} / \mathrm{kg}$ of extract of Bacopa monnieri Linn. Wear observed over the period of 7 days.

In results it was concluded that the extract of Bacopa monnieri Linn. Is found safe, at the dose of $5000 \mathrm{mg} / \mathrm{kg}$. No sign of toxicity at a limit of $5000 \mathrm{mg} / \mathrm{kg}$ of extract of Bacopa monnieri Linn. Were observed over the period of 7 days. 


\subsection{Evaluation of Antidepressant activity of Ethanolic extract of Bacoppa monnieri Linn}

\subsubsection{Forced Swim test}

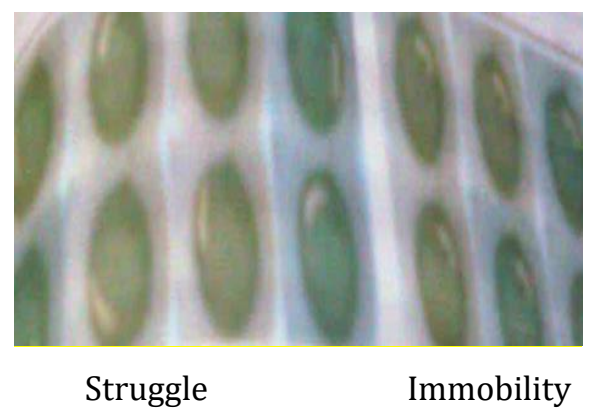

Figure 3 The duration of immobility in the FST is main parameter measured

Table 2 Effect of EEBM on Immobility periods: FST

\begin{tabular}{llll}
\hline Sr. No. & Group for FST & $\begin{array}{l}\text { Dose } \\
(\mathbf{m g} / \mathbf{k g})\end{array}$ & $\begin{array}{l}\text { Immobility Periods (s), } \\
\text { Mean } \pm \text { SEM }\end{array}$ \\
\hline 1 & Negative control & - & \\
2 & Positive control & - & $160.5 \pm 14.20^{* *}$ \\
3 & AMTP & 10 & $70.5 \pm 13.25^{* *}$ \\
4 & Fluoxetine & 10 & $56.5 \pm 5.3^{* *}$ \\
5 & BM & 200 & $95.6 \pm .14 .6^{* *}$ \\
6 & BM & 400 & $76.5 . \pm 6.2^{* *}$ \\
7 & AMTP+BM & $10+200$ & $35.5 \pm 5.1^{* *}$ \\
8 & AMTP+BM & $10+400$ & $17.9 .5 \pm 6.4^{* *}$ \\
9 & Fluoxetine+BM & $10+200$ & $18.9 \pm 1.9^{* *}$ \\
10 & Fluoxetine+BM & $10+400$ & $10.5 \pm 2.7^{* *}$ \\
\hline
\end{tabular}

Stastical Analysis of data was carried out by one way ANOVA followed by Dunnet test values are expressed by mean \pm SEM $\mathrm{P}<0.001$ is considered as criterion significance; ${ }^{* *}=\mathrm{P}<0.001$ as compared to positive control.

3.4.2 Immobility periods in forced swim test

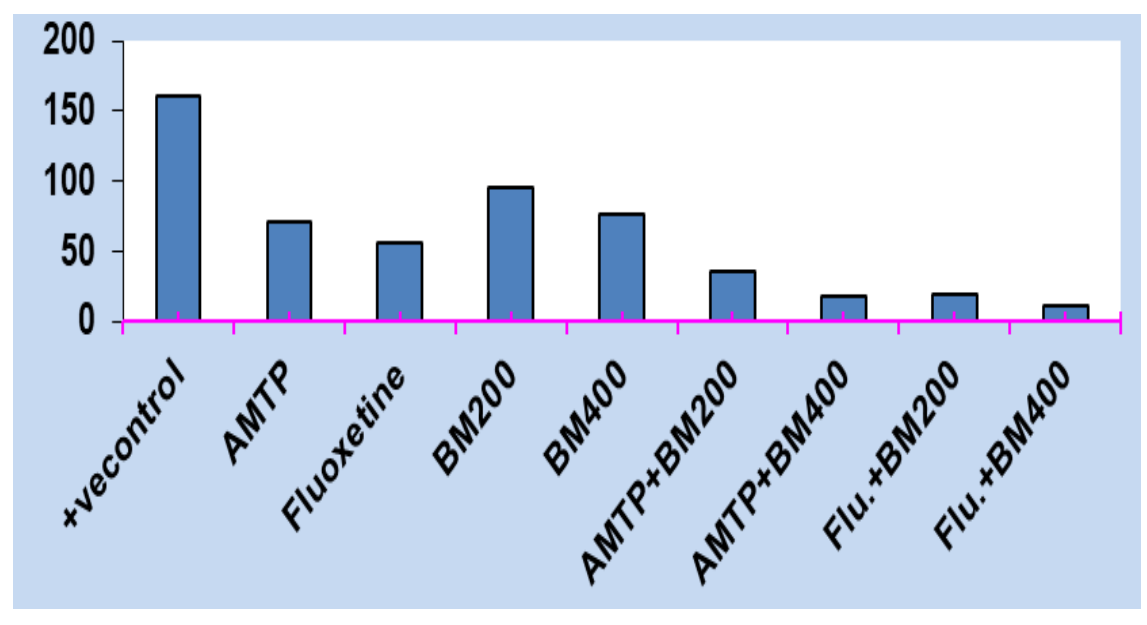

Treatment

Figure 4 Immobility periods in forced swim test 


\subsection{Evaluation of Antidepressant activity of ethanolic extract of Bacoppa monnieri Linn}

\subsubsection{Tail suspension test}

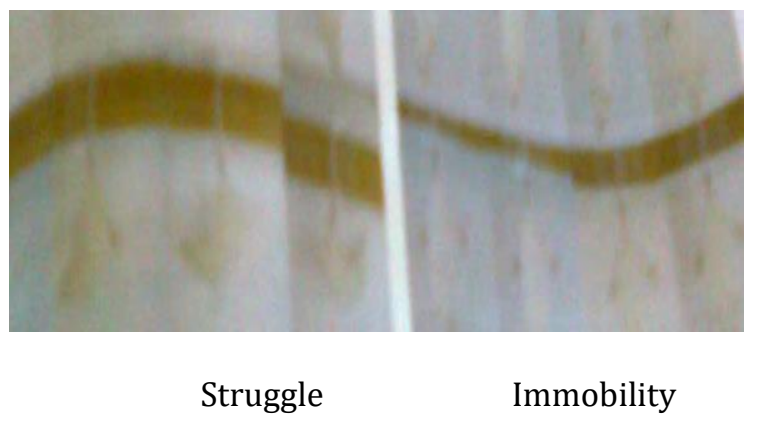

Figure 5 The duration of immobility in the TST is main parameter measured

Table 3 Effect of EEBM on immobility periods in TST

\begin{tabular}{|c|c|c|c|c|}
\hline Sr. No. & Group for TST & Dose (mg/kg) & $\begin{array}{l}\text { Immobility } \\
\text { Mean } \pm \text { SEM }\end{array}$ & (s), \\
\hline 1 & Negative control & - & & \\
\hline 2 & Positive control & - & $163.10 \pm 19.09^{* *}$ & \\
\hline 3 & AMTP & 10 & $90.8 \pm 12.25^{* *}$ & \\
\hline 4 & Fluoxetine & 10 & $91.5 .5 \pm 6.5^{* *}$ & \\
\hline 5 & $\mathrm{BM}$ & 200 & $122.1 \pm .5216^{* *}$ & \\
\hline 6 & $\mathrm{BM}$ & 400 & $102.23 \pm 2.2^{* *}$ & \\
\hline 7 & AMTP+BM & $10+200$ & $54.55 \pm 3.25^{* *}$ & \\
\hline 8 & $\mathrm{AMTP}+\mathrm{BM}$ & $10+400$ & $47.25 \pm 5.43^{* *}$ & \\
\hline 9 & Fluoxetine+BM & $10+200$ & $52.72 \pm 2.10^{* *}$ & \\
\hline 10 & Fluoxetine+BM & $10+400$ & $48.52 \pm 3.98^{* *}$ & \\
\hline
\end{tabular}

3.5.2 Immobility periods in Tail suspension test

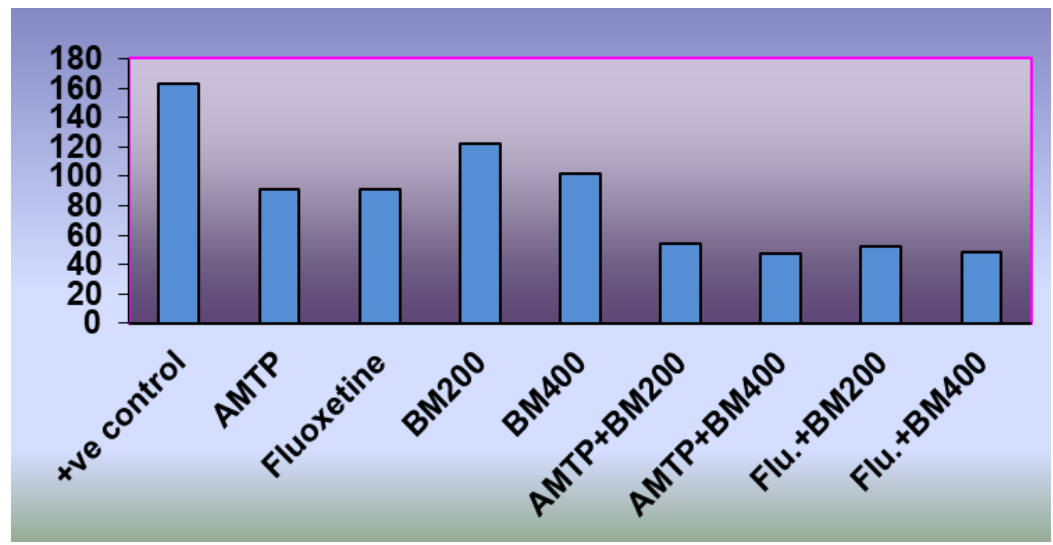

Treatment

Figure 6 Immobility periods in Tail suspension test 


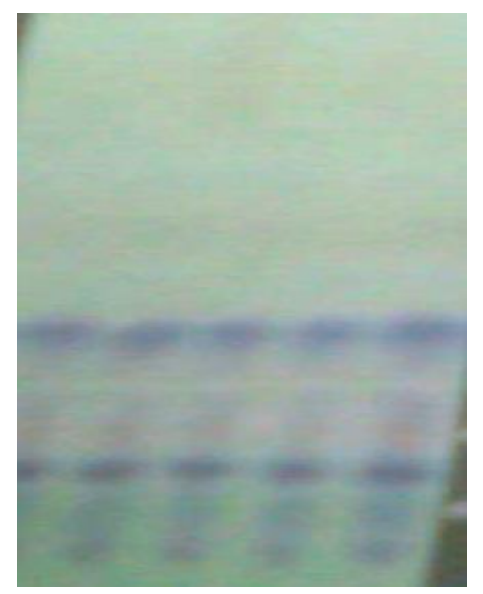

Figure 7 Estimation of free amino acid in mouse brain by TLC-UV-spectrophotometric method GABA: Rf value of $0.33-0.37$; Glutamic Acid: Rf value of 0.13-0.16; Aspartic acid: Rf value of 0.07-0.01.

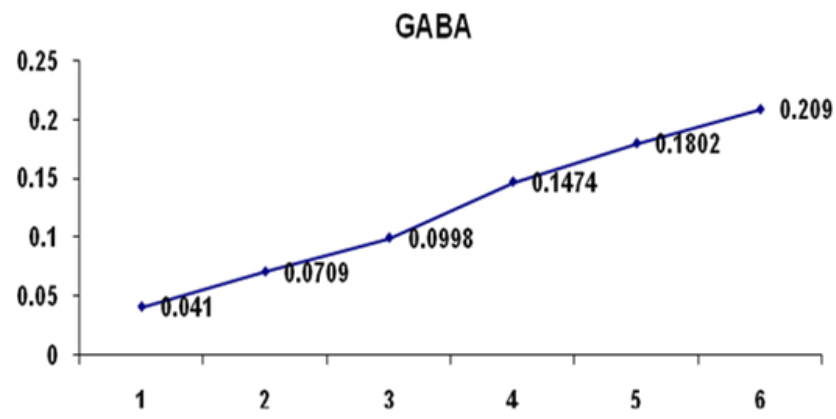

GLUTAMIC ACID
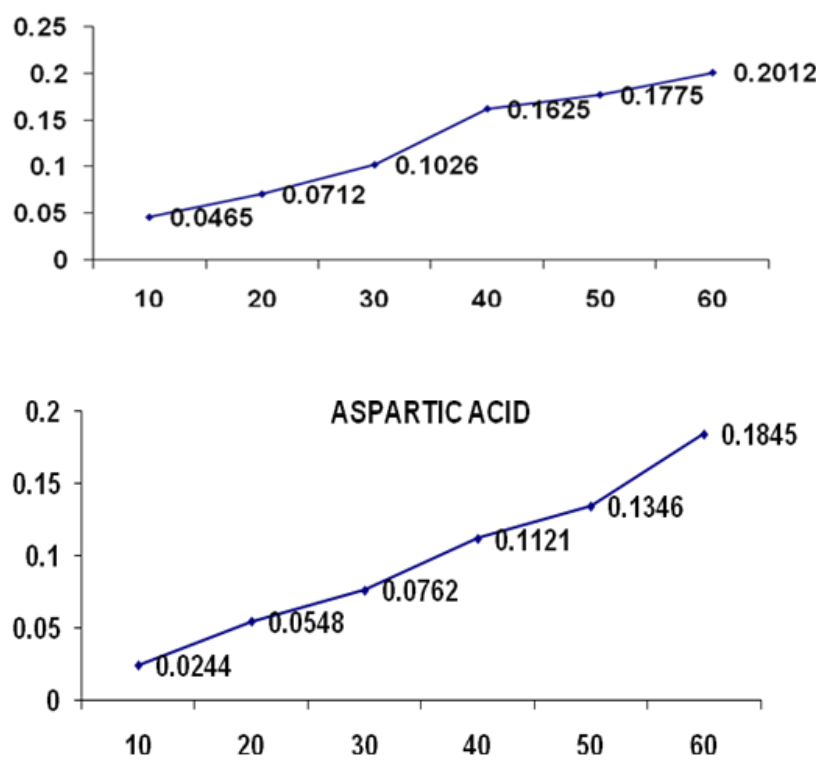

Figure 8 Calibration curve for GABA, Glutamate and Aspartate 
3.6 Estimation of free amino acids in mice brain by forced swim test (FST)

Table 4 Amino acid levels in mice brain ( $\mu$ g per mg of wet tissue)

\begin{tabular}{|c|c|c|c|c|c|}
\hline $\begin{array}{l}\text { Sr. } \\
\text { No. }\end{array}$ & $\begin{array}{l}\text { Group for } \\
\text { FST }\end{array}$ & $\begin{array}{l}\text { Dose } \\
\mu \mathrm{g} / \mathrm{kg}\end{array}$ & $\begin{array}{l}\text { GABA } \\
\text { Mean } \pm \text { SEM }\end{array}$ & $\begin{array}{l}\text { Glutamic acid } \\
\text { Mean } \pm \text { SEM }\end{array}$ & $\begin{array}{l}\text { Aspartic Acid } \\
\text { Mean } \pm \text { SEM }\end{array}$ \\
\hline 1 & $\begin{array}{l}\text { negative control } \\
@\end{array}$ & - & $0.3036 \pm 0.0021$ & $2.113 \pm 0.0212$ & $0.8133 \pm 0.156$ \\
\hline 2 & positive control & - & $0.2470 . \pm 0.0140$ & $1.4425 . \pm 0.012$ & $0.6510 . \pm 0.0129$ \\
\hline 3 & AMTP & 10 & $0.3250 \pm 0.008^{* *}$ & $1.8630 \pm 0.0215^{* *}$ & $0.962 \pm 0.052 * *$ \\
\hline 4 & Fluoxetine & 10 & $0.3770 \pm .0 .004^{* *}$ & $1.9043 \pm .0 .007^{* *}$ & $1.2210 \pm .0 .015^{* *}$ \\
\hline 5 & $\mathrm{BM}$ & 200 & $0.2860 \pm 0.0035^{* *}$ & $1.9755 \pm 0.0310^{* *}$ & $1.9755 \pm 0.031^{* *}$ \\
\hline 6 & $\mathrm{BM}$ & 400 & $0.7160 \pm 0.004^{* *}$ & $2.020 \pm 0.0250^{* *}$ & $0.8745 \pm 0.0145^{* *}$ \\
\hline 7 & AMTP+BM & $10+200$ & $0.3350 \pm 0.0071^{* *}$ & $2.1398 \pm 0.0437^{* *}$ & $0.9510 \pm 0.0137^{* *}$ \\
\hline 8 & AMTP+BM & $10+400$ & $0.3840 \pm 0.048^{* *}$ & $2.4276 \pm 0.0120^{* *}$ & $1.2176 \pm 0.1275^{* *}$ \\
\hline 9 & Fluoxetine+BM & $10+200$ & $0.4021 \pm 0.048^{* *}$ & $2.4810 \pm 0.0140^{* *}$ & $1.5120 \pm 0.0059 * *$ \\
\hline 10 & Fluoxetine+BM & $10+400$ & $0.4434 \pm 0.0102^{* *}$ & $2.7744 \pm 0.010^{* *}$ & $1.5742 \pm 0.022 * *$ \\
\hline
\end{tabular}

3.6.1 Brain GABA concentration in FST

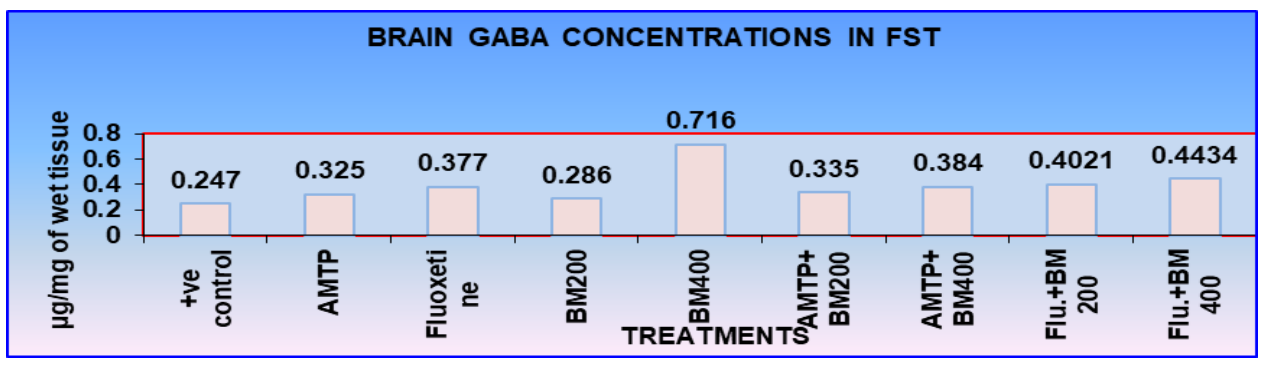

Figure 9 Brain GABA concentration in FST

3.6.2 Brain glutamic acid concentration in FST

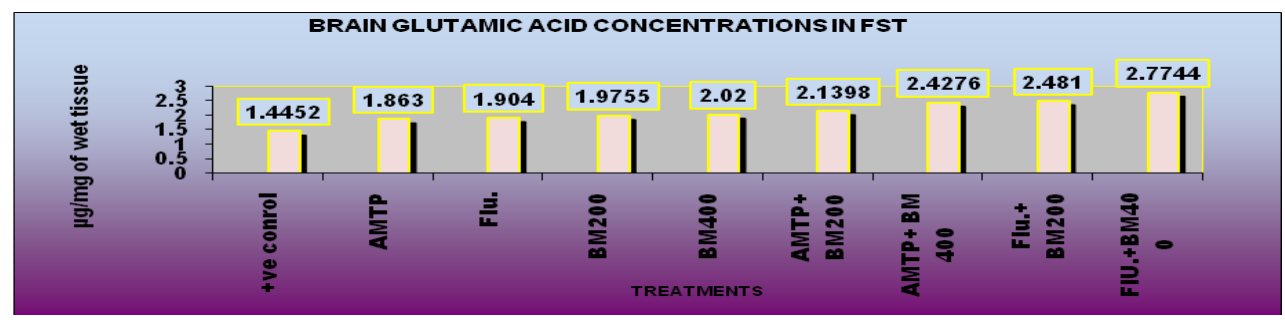

Figure 10 Brain glutamic acid concentration in FST

3.6.3 Brain aspartic acid concentration in FST

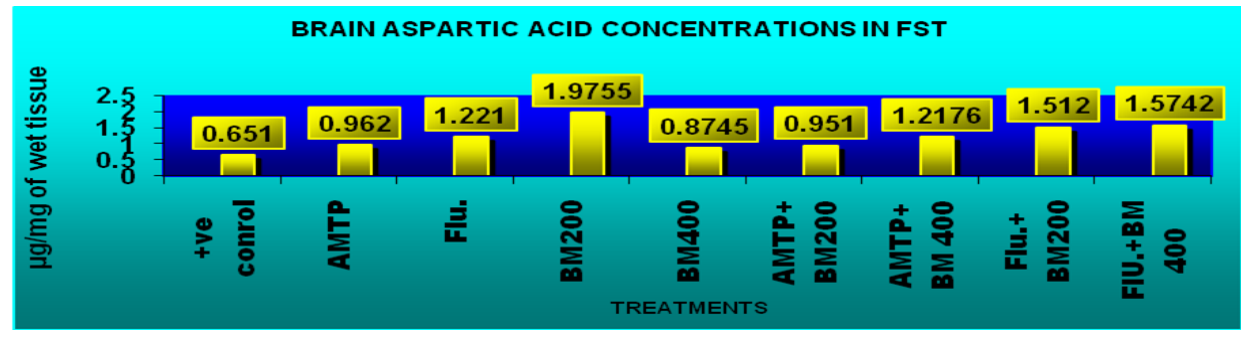

Figure11 Brain aspartic acid concentration in FST [16] 
Values are expressed in $\mu \mathrm{g} / \mathrm{mg}$ of wet tissue. The data is analyzed by one way ANOVA followed by Dunnetts test. ${ }^{* *} \mathrm{p}<0.001$ as compared to positive control. The brain GABA concentrations, Glutamic Acid concentrations, Aspartic Acid concentrations in forced swim test wear found to be significantly $(p<0.01)$ increasing in animals treated with Amitriptylene, Fluoxetine, EEBM200, EEBM400 and with combination of Amitriptylene + EEBM and Fluoxetine+ EEBM as compared to control animals.

\subsection{Estimation of free amino acids in mice brain tail suspension test (TST)}

Table 5 Amino acid levels in mice brain in TST amino acid Conc. in mice brain ( $\mu$ g per mg of wet tissue)

\begin{tabular}{llllll}
\hline $\begin{array}{l}\text { Sr. } \\
\text { No. }\end{array}$ & Group for & $\begin{array}{l}\text { Dose } \\
\text { TST }\end{array}$ & $\begin{array}{l}\text { GAB } / \mathbf{k g} \\
\text { Mean } \pm \text { SEM }\end{array}$ & $\begin{array}{l}\text { Glutamic acid } \\
\text { Mean } \pm \text { SEM }\end{array}$ & $\begin{array}{l}\text { Aspartic Acid } \\
\text { Mean } \pm \text { SEM }\end{array}$ \\
\hline 1 & negative control @ & - & $0.3036 \pm 0.0031$ & $2.113 \pm 0.0212$ & $0.8133 \pm 0.156$ \\
2 & positive control & - & $0.2148 . \pm 0.0170$ & $1.4625 . \pm 0.0114$ & $0.5590 . \pm 0.0161$ \\
3 & AMTP & 10 & $0.2598 \pm 0.0108^{* *}$ & $2.2215 \pm 0.0245^{* *}$ & $0.3122 \pm 0.0125^{* *}$ \\
4 & Fluoxetine & 10 & $0.3080 \pm .0 .0160^{* *}$ & $2.2595 \pm .0 .0152^{* *}$ & $1.4495 \pm .0 .0285^{* *}$ \\
5 & BM & 200 & $0.2195 \pm 0.0165^{* *}$ & $1.9755 \pm 0.0310^{* *}$ & $0.945 \pm 0.0165^{* *}$ \\
6 & BM & 400 & $0.2565 \pm 0.0250^{* *}$ & $2.1310 \pm 0.0550^{* *}$ & $1.1198 \pm 0.0245^{* *}$ \\
7 & AMTP+BM & $10+200$ & $0.3564 \pm 0.0278^{* *}$ & $2.5924 \pm 0.0237^{* *}$ & $1.4012 \pm 0.0147^{* *}$ \\
8 & AMTP+BM & $10+400$ & $0.4202 \pm 0.0152^{* *}$ & $2.8276 \pm 0.0232^{* *}$ & $1.6385 \pm 0.0175^{* *}$ \\
9 & Fluoxetine+BM & $10+200$ & $0.4610 \pm 0.0240^{* *}$ & $3.095 \pm 0.045^{* *}$ & $1.5445 \pm 0.0227^{* *}$ \\
10 & Fluoxetine+BM & $10+400$ & $0.4895 \pm 0.0195^{* *}$ & $3.2764 \pm 0.0575^{* *}$ & $1.7310 \pm 0.0234^{* *}$ \\
\hline \multicolumn{2}{c}{$@$ : Unstressed animal i.e. Normal animal } &
\end{tabular}

3.7.1 Brain GABA

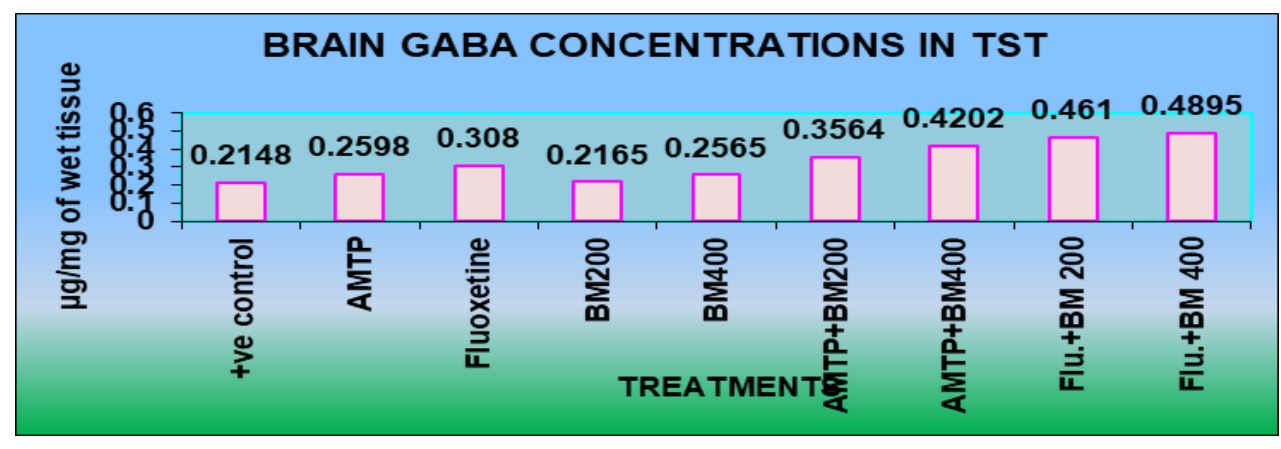

Figure 12 Brain GABA concentration TST

3.7.2 Brain glutamic acid concentration in TST

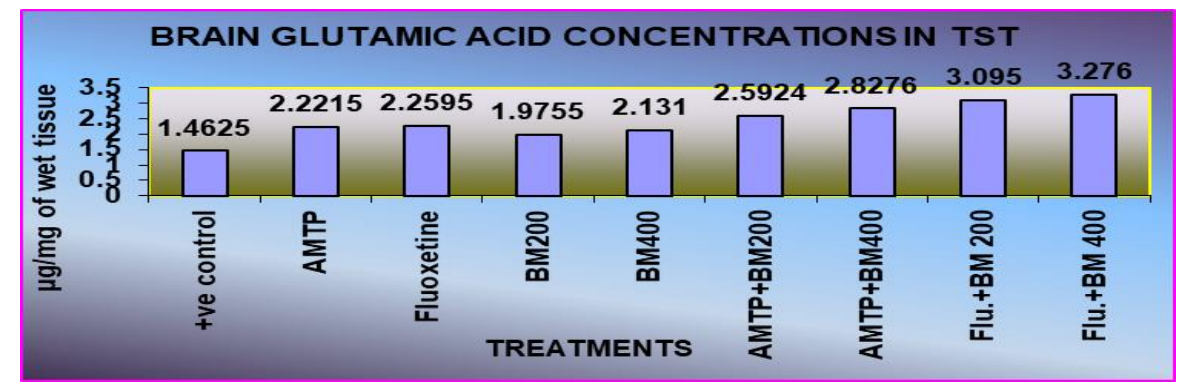

Figure 13 Brain glutamic acid concentration in TST 


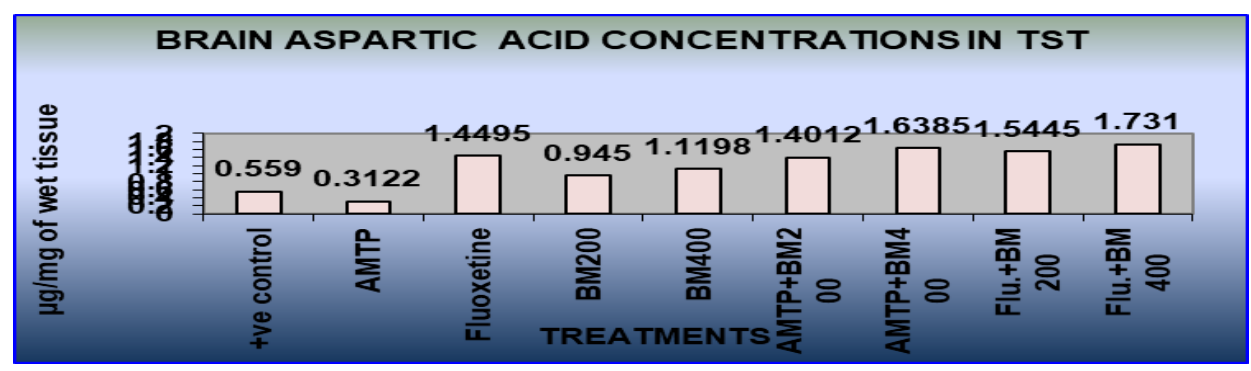

Figure 14 Brain aspartic acid concentration in TST

Values are expressed in $\mu \mathrm{g} / \mathrm{mg}$ of wet tissue. The data is analyzed by one way ANOVA followed by Dunnetts test. ${ }^{* *} \mathrm{p}<0.001$ as compared to positive control. The brain GABA concentrations, Glutamic Acid and Aspartic Acid concentrations in Tail Suspension test wear found to be significantly $(p<0.01)$ increasing in animals treated with Amitriptylene, Fluoxetine, EEBM200,EEBM400 \& with combination of Amitriptylene+EEBM and Fluoxetine+ EEBM as compared to control animals.

\subsection{Estimation of acetylcholine esterase activity in mice brain by spectrophotometric method}

Table 6 Acetylcholine esterase activity FST and TST Acetylcholine esterase activity $(\mu \mathrm{mo} / \mathrm{l} / \mathrm{min} / \mathrm{gm}$ of tissue)

\begin{tabular}{lllll}
\hline Sr. No. & Group FST & $\begin{array}{l}\text { Dose }(\mathrm{mg} / \mathrm{kg}) \\
\mu \mathrm{g} / \mathrm{kg}\end{array}$ & $\begin{array}{l}\text { FST } \\
\text { Mean } \pm \text { SEM }\end{array}$ & $\begin{array}{l}\text { TST } \\
\text { Mean } \pm \text { SEM }\end{array}$ \\
\hline 1 & negative control @ & - & $164 \pm 1.3325^{* *}$ & $164 \pm 1.3325^{* *}$ \\
2 & positive control & - & $135 \pm 1.615$ & $184 \pm .6 .025$ \\
3 & AMTP & 10 & $140 \pm 3.744^{* *}$ & $158 \pm 3.495^{* *}$ \\
4 & Fluoxetine & 10 & $152 \pm 5.198^{* *}$ & $154 \pm 3.498^{* *}$ \\
5 & BM & 200 & $167 \pm 3.286^{* *}$ & $168 \pm 2.765^{* *}$ \\
6 & BM & 400 & $158 \pm 4.405^{* *}$ & $160 \pm 3.876^{* *}$ \\
7 & AMTP+BM & $10=200$ & $135 \pm 2.741^{* *}$ & $148 \pm 3.165^{* *}$ \\
8 & AMTP+BM & $10+400$ & $132 \pm 5.185^{* *}$ & $147 \pm 3.425^{* *}$ \\
9 & Fluoxetine+BM & $10+200$ & $148 \pm 4.325^{* *}$ & $151 \pm 3.892^{* *}$ \\
10 & Fluoxetine+BM & $10+400$ & $138 \pm 5.454^{* *}$ & $138 \pm 5.258^{* *}$ \\
\hline
\end{tabular}

3.8.1 Acetylcholine esterase activity FST:

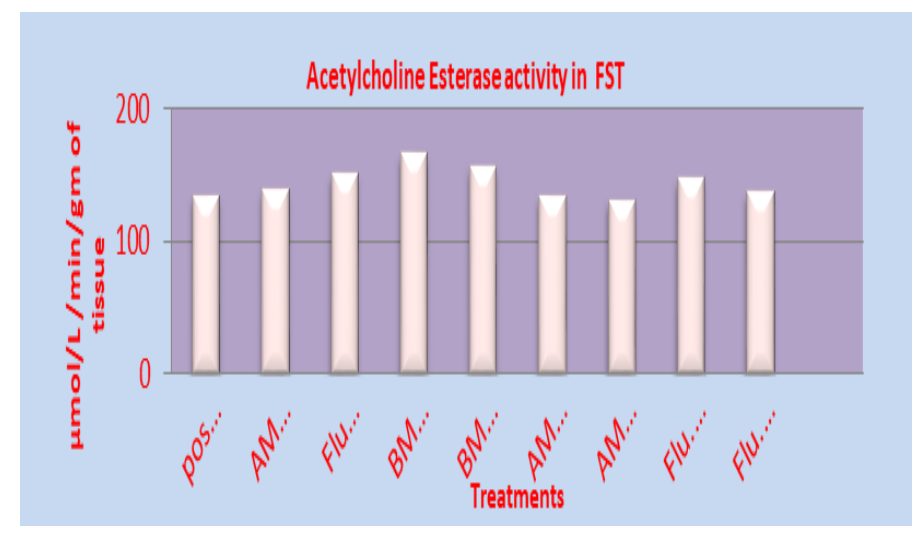

Figure 15 Acetylcholine Esterase activity (FST) 
The data is analyzed by one way ANOVA followed by Dunnetts test. ${ }^{* *} \mathrm{p}<0.001$ as compared to positive control. The brain Acetylcholine Esterase activity in Force Swim Test wear found to significantly $(\mathrm{p}<0.01)$ decreasing in animals treated with Amitriptylene, Fluoxetine, EEBM 200, EEBM 400and with combination of Amitriptylene+EEBM and Fluoxetine+ EEBM as compaired to control animals.

\subsubsection{Acetylcholine esterase activity TST}

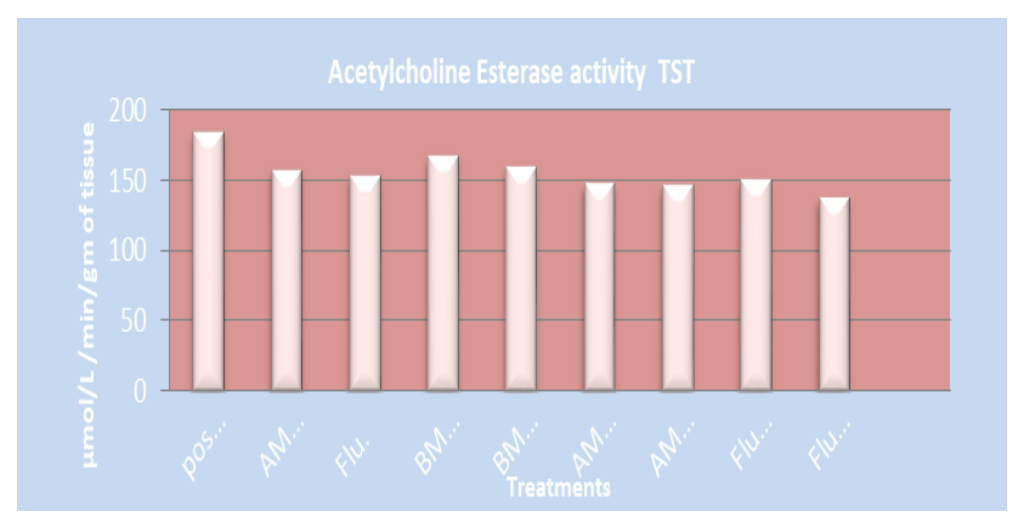

Figure 16 Acetylcholine esterase activities (TST)

The data is analyzed by one way ANOVA followed by Dunnetts test. ${ }^{* *} \mathrm{p}<0.001$ as compared to positive control. The brain Acetylcholine Esterase activity in Tail Suspension Test wear found to significantly $(\mathrm{p}<0.01)$ decreasing in animals treated with Amitriptylene, Fluoxetine, EEBM 200, EEBM 400and with combination of Amitriptylene+EEBM and Fluoxetine+EEBM as compared to control animals.

\section{Discussion}

The role of GABA in depressive illness is overshadowed because of overemphasis on the monoamine depletion theory. In separate studies it has been shown that administration of either of the two GABA-A agonists muscimol of THIP ,decreased the CMS induced immobility time in experimental animals, amino acetic acid a drug that elevates brain GABA levels, had a similar effect [15]. The GABA-mimetic Bacopa monnieri decreased the immobility in forced swim test model of depression. Reports that GABAergic activity tends to be lower in the depressed state than in the normal brain in rodents models of depression as well as in human with depression are summarized [14], which is in sharp contrast with other perceptibility logical reports of elevated GABA levels after chronic mild stress [16].

In this study the GABA concentrations are found to follow similar profile .In control groups in both FST and TST the GABA levels wear found to be decreased as compared to basal values i.e. GABA levels in unstressed normal animals. Also that the decrease in GABA levels after CMS in FST and TST wear attenuated dose dependently in animals receiving Bacopa monnieri Linn extract as well those receiving Amitriptylene and floxetine. Similar increase in GABA concentrations wear observed in Amitriptylene+ethanolic extraction of Bacoppa monnieri Linn And Floxatine+ethanolic extraction of Bacoppa monnieri Linn. levels of glutamic acid and aspartic acid wear also increased dose dependently in animals pretreated with Bacoppa monnieri Linn extracts and those with amitriptylene and fluoxetine.

The co-administration of ethanolic extract of Bacoppa monnieri Linn extracts and Amitriptylene as well as fluoxetine yielded similar results. It appears that the total free amino acid turnover in different regions of brain is decreased after chronic mild stress in both FST and TST which is attenuated by pretreatment with antidepressants Amitriptylene and Fluoxetine as well as that with ethanolic extract of Baccopa monnieri Linn extract. The present study revealed that there was significant increase in Acetylcholine esterase activity in positive control animals undergoing FST and TST as compared to negative Control animals.

It has been reported that Acetylcholine levels wear decreased with corresponding increase in Acetylcholine esterase activity after chronic mild stress in FST and TST $[17,18]$. Also that Acetylcholine esterase activity was significantly decreased in animals pretreated with Ethanolic extract of Bacoppa monnieri Linn, Amitriptylene and Fluoxetine in both FST and TST was also observed. Similar results but further decrease in Acetylcholine esterase activity in animals co-administered with ethanolic extract of Bacoppa monnieri Linn. Amitriptylene and Fluoxetine in both FST and TST was also observed. 


\section{Conclusion}

From the experimental evidences it may be conclude that, ethanolic extract of Bacoppa monnieri Linn possesses significant antidepressant activity. Future scope will be increased for combination therapy and it may be improved the mechanism of action, less side effect.

\section{Compliance with ethical standards}

\section{Acknowledgments}

I am thankful to Dr. D.R. Mundhada sir and Mr. Dinesh Wanjari for providing all facilities.

\section{Disclosure of conflict of interest}

The authors declare that there is no conflict of interest regarding the publication of this paper.

\section{Statement of ethical approval}

In present research work on mouse brain performed experiments and Institutional animal ethical committee approved for research work.

\section{References}

[1] Roodenrys S, Booth D, Bulzomi S, Phipps A, Micallef C and Smoker J. (2002). Chronic effects of Brahmi (Bacopa monnieri) on human memory. Neuropsychopharmacology (Wollongong), 27 (2), 279-81.

[2] Stough C, Lloyd J, Clarke J, Downey L, Hutchison C, Rodgers T and Nathan P. (2001). The chronic effects of an extract of Bacopa monniera (Brahmi) on cognitive function in healthy human subjects. Psychopharmacology (Berl), 156 (4), 481-4.

[3] Mukundh N, Balasubramanian, Muralidharan P and Balamurugan G. (2012). The transcription factor network associated with Amino acid response in mammalian cell Department of Biochemistry and Molecular Biology, University of Florida College of Medicine, Gainesville, FL, 4(4), 310-313.

[4] Gohil KJ and Patel JA. (2010). A review on Bacopa monnieri current research \& future prospects. International Journal of Green Pharmacy J sterol, 215-219.

[5] Anderson IM. (2001). Meta-analytical studies on new antidepressants. British Medical Bulletin, 57,161-178.

[6] Harrison Tr, Kasper DL, Brauvolt E, Fax AS. (2005) Harrisons Principles of Internal Medicine, $16^{\text {th }} e^{\text {n }}$, Mcgraw Hill Publications, New York, 2549-2554.

[7] Baldessarini RJ and Tohen M. (1988). Is there a long-term protective effect of mood-altering agents in unipolar depressive disorder? In, Psychopharmacology: Current Trends. (Casey, D.E., and Christensen, A.V, eds.) Springer-Verlag, Berlin: 130-139.

[8] Blier P, de Montigny C and Chaput Y. (1990). A role for the serotonin system in the mechanism of action of antidepressant treatments: preclinical evidence. J. Clin. Psychiatry, 51(suppl), 14-20.

[9] Bodkin JA, Zornberg GL, Lukas SE and Cole JO. (1995). Buprenorphine treatment of refractory depression. Journal of Clinical Psychopharmacology, 15 (1), 49-57.

[10] Schreiber S, Bleich A and Pick CG. (2002). Venlafaxine and mirtazapine: different mechanism of antidepressant action, common opioid-mediated antinociceptive effects--a possible opioid involvement in severe depression? J Molecular Neuroscience, 13 (1-2), 143-9.

[11] Kasa K. (1982). Cerebrospinal fluid gamma_amino butyric acid and homovanillin acid in depressive disorders. Biolpsychiatry, 8, 877-83.

[12] Krystal JH, Sanacora G, Blumberg H, Anand A, Charney DS, Marek G, Epperson CN, Goddard A and Mason GF. (2002). Glutamate and GABA systems as targets for novel antidepressant and mood-stabilizing treatments. Molecular psychiatry, 7(S1), S71. 
[13] Calon F, Morissette M, Goulet M, Grondin R, Blanchet PJ, Bédard PJ and Di Paolo T. (1999). Chronic D1 and D2 dopaminomimetic treatment of MPTP-denervated monkeys: effects on basal ganglia GABAA/benzodiazepine receptor complex and GABA content. Neurochemistry international, 35(1), 81-91.

[14] Rada P, Colasante C, Skirzewski M, Hernandez L and Hoebel B. (2006). Behavioral depression in the swim test causes a biphasic, long-lasting change in accumbens acetylcholine release, with partial compensation by acetylcholinesterase and muscarinic-1 receptors. Neuroscience, 141(1), 67-76.

[15] Giacobini E. (2004). Cholinesterase inhibitors: new roles and therapeutic alternatives. Pharmacological research, 50(4), 433-440.

\section{How to cite this article}

Mankar SS, Turan SP, Mankar SS and Shelke PA. (2019). Antidepressant in animal models of depression and study of cognitive property. GSC Biological and Pharmaceutical Sciences, 7(3), 64-76. 